\title{
Functional neuroimaging in psychiatry
}

\author{
Gynthia H. Y. Fu* and Philip K. McGuire
}

Section of Neuroimaging, Department of Psychological Medicine, Institute of Psychiatry and Kings College School of Medicine, Denmark Hill, London SE5 8AF, UK

\begin{abstract}
Functional neuroimaging is one of the most powerful means available for investigating the pathophysiology of psychiatric disorders. In this review, we shall focus on the different ways that it can be employed to this end, describing the major findings in the field in the context of different methodological approaches. We will also discuss practical issues that are particular to studying psychiatric disorders and the potential contribution of functional neuroimaging to future psychiatric research.
\end{abstract}

Keywords: neuroimaging; psychiatry; single photon emission tomography; PET; fMRI; schizophrenia

\section{INTRODUCTION}

Psychiatric disorders involve abnormalities in thought, behaviour and mood. Understanding the mechanisms underlying these conditions has progressed from the notions that an imbalance of black bile caused melancholia to complex formulations of interacting genetic, social, psychological and environmental factors (Gelder 1996). Although the manifestations of psychiatric illnesses are difficult to attribute to focal cerebral lesions, these disorders of the mind must ultimately reflect a brain dysfunction. The advent of neuroimaging has provided an unprecedented opportunity to relate abnormalities of cognition and behaviour to changes in brain function.

\section{STUDIES OF THE RESTING STATE}

Initial neuroimaging studies simply sought to establish the involvement of the brain in psychiatric illnesses and examined brain activity in patients in the 'resting' state. Ingvar \& Franzen (1974) used the intra-arterial ${ }^{133} \mathrm{Xe}$ technique to compare regional cerebral blood flow in schizophrenic patients with that in controls. Although there was no significant difference in their global cerebral blood flow, patients did not show the increased activity in frontal relative to posterior regions that was evident in controls. Ingvar \& Franzen (1974) thus coined this abnormality 'hypofrontality'. Since their classic study, numerous groups have replicated this finding using the ${ }^{133}$ Xe inhalation technique (Kurachi et al. 1985; Berman et al. 1986; Chabrol et al. 1986; Weinberger et al. 1986; Geraud et al. 1987; Mathew et al. 1988), particularly in the pre-frontal cortex (Berman et al. 1986; Weinberger et al. 1986), although some have not (Mathew et al. 1982; Gur et al. 1983, 1985).

Subsequent resting studies in schizophrenia using single photon emission tomography (SPET) and positron emission tomography (PET) have found hypofrontality (Buchsbaum et al. 1982; Brodie et al. 1984; Farkas et al. 1984; Wolkin et al. 1985; Kishimoto et al. 1987; Volkow

*Author for correspondence (c.fu@iop.kcl.ac.uk). et al. 1987; Vita et al. 1995), particularly in the prefrontal (Vita et al. 1995) and left frontal cortices (Buchsbaum et al. 1982; Brodie et al. 1984), although again there have also been reports of no difference in anterior-posterior cerebral activity (Sheppard et al. 1983; Widen et al. 1983; Kling et al. 1986; Early et al. 1987; Gur et al. 1987a,b; Kishimoto et al. 1987; Berman et al. 1993) and even 'hyperfrontality' (Szechtman et al. 1988; Cleghorn et al. 1989; Ebmeier et al. 1993). Another major finding has been of increased activity in the basal ganglia. This appears to be secondary to treatment with anti-psychotic medication (Brodie et al. 1984; Buchsbaum et al. 1987, 1992; Szechtman et al. 1988; Wik et al. 1989; Holcomb et al. 1996; Wolkin et al. 1996; Cohen et al. 1997; Miller et al. 1997; Scottish Schizophrenia Research Group 1998), consistent with increased activity in the putamen following a single anti-psychotic dose in healthy volunteers (Bartlett et al. 1998).

As in schizophrenia, initial functional imaging studies of depression involved the resting state. Most have described hypofrontality (Baxter et al. 1989; Hurwitz et al. 1990; Martinot et al. 1990; Sackeim et al. 1990; Austin et al. 1992; Bench et al. 1992; Biver et al. 1994), particularly in the dorsolateral prefrontal (Baxter et al. 1989; Bench et al. 1992; Biver et al. 1994) and anterior cingulate cortices (Bench et al. 1992), although some reported no difference in anterior-posterior cerebral activity (Gur et al. 1984; Baxter et al. 1985; Kling et al. 1986; Silfverskiold \& Risberg 1989; Berman et al. 1993) and increased left prefrontal cortical activity (Drevets et al. 1992a). Several groups have also described decreased activity in the caudate (Baxter et al. 1985; Buchsbaum et al. 1986; Austin et al. 1992) and other regions in the basal ganglia (Buchsbaum et al. 1986; Hurwitz et al. 1990; Austin et al. 1992).

In contrast, in obsessive-compulsive disorder (OCD), the converse seems to apply, with relative hyperfrontality, particularly in the inferior prefrontal cortex (for a review, see Saxena et al. 1998) and increased resting caudate glucose metabolism (Baxter et al. 1987, 1988), although the latter has not been consistently replicated (Nordahl et al. 1989; Swedo et al. 1989). 


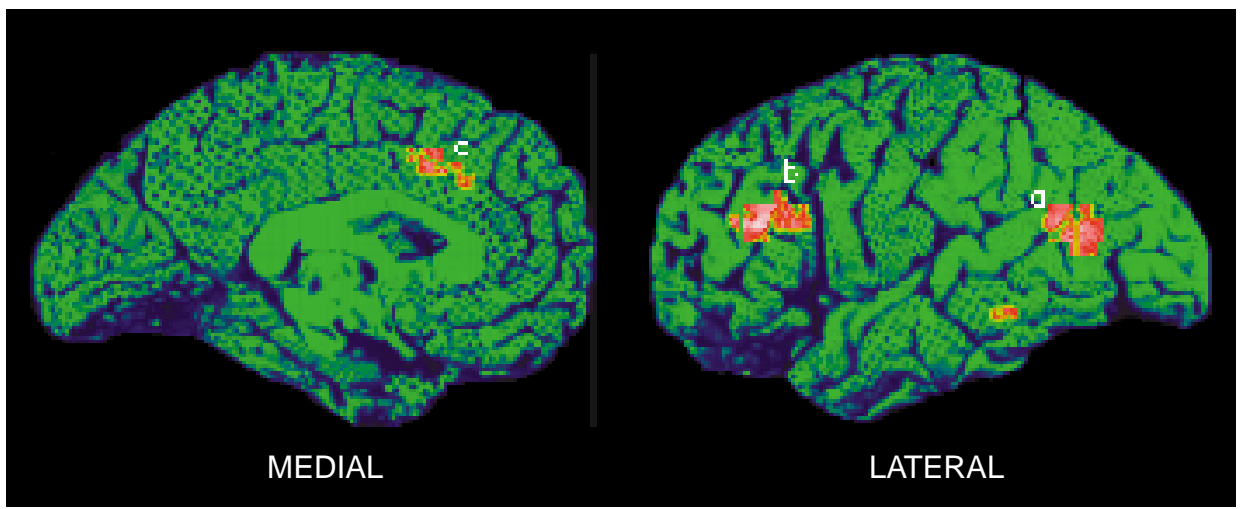

Figure 1. Medial and lateral views showing relatively decreased resting blood flow in the inferior parietal cortex $(a)$, dorsolateral prefrontal $(b)$ and anterior cingulate $(c)$ in patients with depression, as measured using $\mathrm{C}^{15} \mathrm{O}_{2}$ PET. From Bench et al. (1993).

The fundamental problem in interpreting these results is that it is difficult to ascertain the subject's cognitive activity during the resting state. The latter probably involves a variety of cognitions and emotional processes which differ from person to person and are associated with correspondingly different patterns of regional cerebral activity (Mazziotta et al. 1992; Andreasen et al. 1995; McGuire et al. 1996a). In an ${ }^{18}[\mathrm{~F}]$ fluoro-deoxyglucose $\left({ }^{18} \mathrm{FDG}\right)$ PET study of normal individuals, Mazziotta $e t$ al. (1992) showed that the form of the resting condition itself (eyes closed versus ears blocked versus both eyes closed and ears blocked) affected the pattern of cerebral activity. Several authors have thus concluded that the term 'resting state' is something of a misnomer (Mazziotta et al. 1992; Andreasen et al. 1995; Frith et al. 1995). These initial studies, which used the resting state paradigm, have revealed evidence of cerebral dysfunction in psychiatric disorders. The next step was to explore the nature of these abnormalities.

\section{SYMPTOMS AND RESTING ACTIVITY}

One approach which attempts to address the issue of heterogenous cognitive activity during the resting state is to correlate resting activity with ratings of different psychiatric symptoms. Liddle et al. (1992) used PET to examine the relationship between cerebral blood flow and three symptom clusters in schizophrenic patients. They found that 'negative' symptoms were inversely correlated with prefrontal blood flow, while thought disorder was correlated with cingulate activity and hallucinations and delusions were correlated with blood flow in the medial temporal cortex. They concluded that each subsyndrome involved a different distributed neuronal network.

Bench et al. (1993) used a similar approach in depressed patients using $\mathrm{C}^{15} \mathrm{O}_{2}$ PET. Dividing the symptoms into three factors, they found that anxiety correlated positively with blood flow in the posterior cingulate and inferior parietal cortices, while psychomotor retardation and depressed mood correlated negatively with blood flow in the left dorsolateral prefrontal and parietal cortices and cognitive performance correlated positively with blood flow in the left medial prefrontal cortex (figure 1). Drevets et al. (1997) reported that the cortex ventral to the genu of the corpus callosum had abnormally decreased activity in both unipolar and bipolar depressed patients. Conversely, in a small group of bipolar manic patients, they found increased activity in this region which suggests that its activity may be mood-state depen- dent (Drevets et al. 1997). Correlating resting activity with symptom ratings has thus proven fruitful, with the caveat that ratings are made outside the scanner and therefore may not correspond to the mental state during image acquisition.

\section{COGNITIVE TASKS}

Measuring activation during the performance of a cognitive task has been the most common approach used in functional neuroimaging in general to assess 'on-line' mental state and has been extensively employed in studies of psychiatric disorders. One of the best examples is the use of tasks believed to engage the prefrontal cortex in order to investigate cognitive function in schizophrenia. These have included the Continuous Performance Test, Wisconsin Card Sorting Test (WCST), Raven Progressive Matrices, Tower of London and tests of working memory (Andreasen et al. 1992; Weinberger \& Berman 1996); all of which have been associated with reduced prefrontal activation in patients with schizophrenia as compared to healthy subjects (Weinberger \& Berman 1996). An important consideration with this approach is whether behavioural performance on the task is measured on-line during scanning, as psychiatric patients typically perform at a lower level than controls. It is still unclear whether reduced prefrontal activation in schizophrenia leads to poor task performance or vice versa. Examination of patients with Huntington's disease who had comparably impaired performance as schizophrenic patients failed to show abnormal prefrontal activation during the WCST, suggesting that this cannot simply be attributed to poor performance (Weinberger et al. 1988; Goldberg et al. 1990). However, in studies of verbal fluency in which the rate of response was paced such that schizophrenic patients were able to perform at the same level as controls, there were no differences in frontal activation (Frith et al. 1995). Nevertheless, even when patients and controls are responding with similar speed and accuracy, one group may still be having to work harder to attain this performance level than the other.

In recent work using $\mathrm{H}_{2}{ }^{15} \mathrm{O}$ PET, Fletcher et al. (1998) examined prefrontal cortical blood flow in schizophrenia during a graded memory task. When recalling only a few words, patients showed equivalent performance to controls and similar prefrontal activation, but as the number of words increased, placing more demands on recall, their performance deteriorated. This declining performance was associated with a failure to increase 


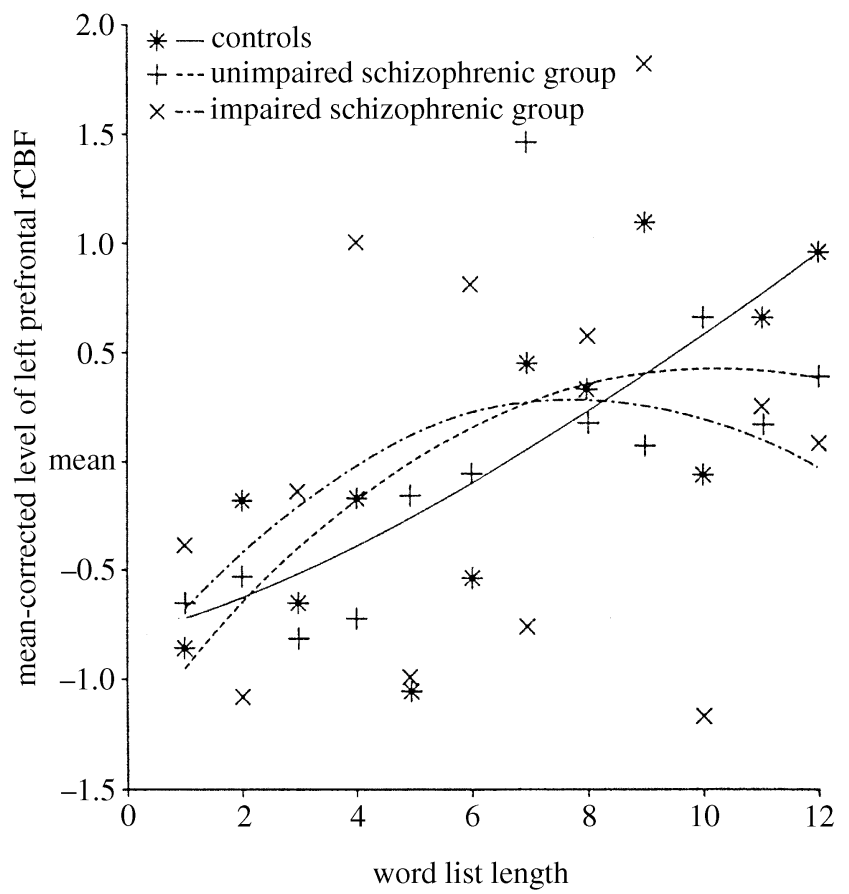

Figure 2. Differential activation in the left prefrontal cortex in patients with schizophrenia and controls with increasing word length in a memory retrieval task. Controls showed increasing activation as the list length increased. In memory-impaired and memory-unimpaired patients with schizophrenia this relationship appeared to break down at longer list lengths, when task demands were maximal. rCBF indicates regional cerebral blood flow. From Fletcher et al. (1998).

prefrontal blood flow in parallel with the increasing task load. These data suggest that an attenuated prefrontal response may only be evident when patients cannot meet the task demands (figure 2).

Abnormal prefrontal activation in schizophrenia may also vary with the nature of the task being performed. Curtis et al. $(1998,1999)$ found that schizophrenic patients showed an attenuated prefrontal activation during verbal fluency, but not during a semantic decision task (figure 3). Although both tasks engage verbal processing and are normally associated with prefrontal activation, verbal fluency requires the generation of words from a cue, whereas semantic decision involves the categorization of an external stimulus. This suggests that in this context reduced prefrontal activation may be related to impaired intrinsic generation in schizophrenia. Spence et al. (1998) used $\mathrm{H}_{2}{ }^{15} \mathrm{O}$ PET to study schizophrenic and healthy men as they made random and cued joystick movements. When patients were acutely psychotic, they showed a left dorsolateral prefrontal cortical hypoactivation relative to controls but, when in remission, this difference in activation also 'remitted'. Thus, attenuated prefrontal activation in schizophrenia may also be related to the severity of psychotic symptoms at the time of scanning.

\section{5. 'CAPTURING' SYMPTOMS}

Some studies have explicitly sought to examine the neural correlates of the symptoms being experienced while the patient is scanned. Using ${ }^{18}$ FDG PET, Cleghorn et al. (1992) compared patients who had experienced (a)

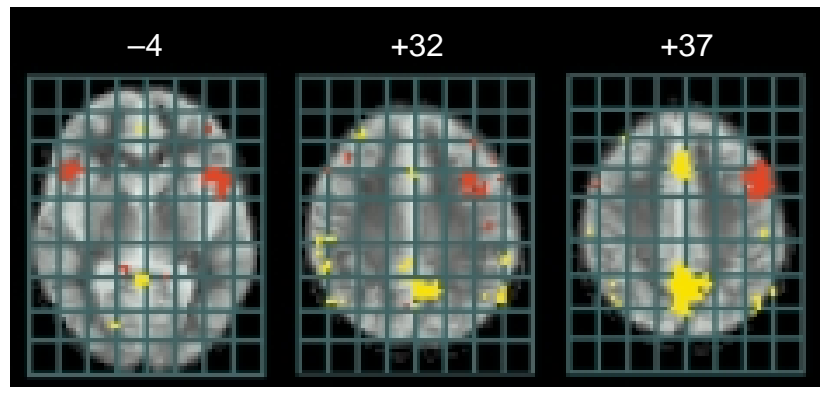

(b)

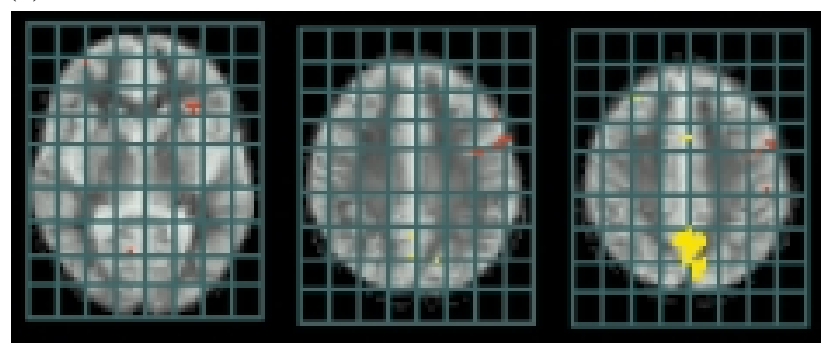

(c)

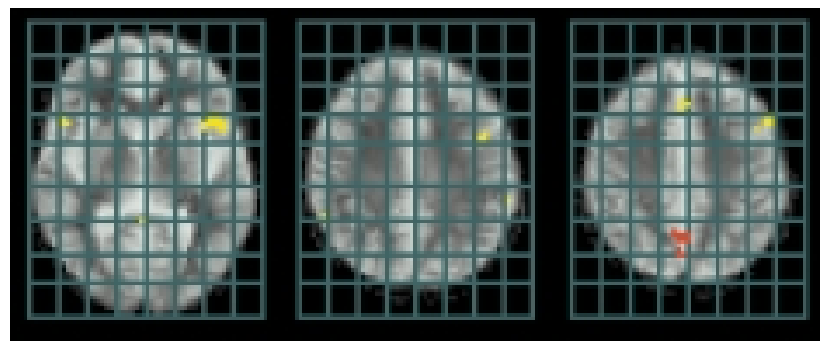

Figure 3. Attenuated activation of the prefrontal cortex in an fMRI study of verbal fluency in schizophrenia. Activation is shown on transverse generic brain activation maps at $-4 \mathrm{~mm}$ below and $32 \mathrm{~mm}$ and $37 \mathrm{~mm}$ above the intercommissural plane, respectively. The left side of each map represents the right side of the brain. (a) Control subjects showed marked activation in the inferior frontal cortex and left dorsolateral prefrontal cortex (red voxels). (b) Patients with schizophrenia showed an attenuated response in these regions, and $(c)$ direct comparison of the two groups confirmed that these differences in prefrontal activation were significant. From Curtis et al. (1998).

auditory hallucinations during scanning and patients who had not. Those who reported having hallucinations, when debriefed after scanning, had lower relative metabolism in lateral temporal regions with a trend towards higher metabolism in the right inferior frontal cortex (Cleghorn et al. 1992). McGuire et al. (1993) examined schizophrenic patients when they were actively experiencing auditory hallucinations and again when the hallucinations had resolved. The timing of the image acquisition was based on the patient signalling the onset of a hallucination by moving their finger. Cerebral blood flow was greater during the hallucinating than the non-hallucinating state in the left inferior frontal region, with trends towards greater blood flow in the left anterior cingulate and temporal cortices. Silbersweig et al. (1995) adopted a similar approach, using PET to examine blood flow when patients signalled the presence of hallucinations via a button press. Hallucinations were correlated with activity in the striatum, thalamus and medial temporal cortex. 
These studies were designed to 'capture' the neural correlates of the symptom of interest, in this case auditory hallucinations. However, as psychiatric symptoms are often subjective experiences, the quality of the data ultimately depends on the reliability of the patient's report. Furthermore, the process of signalling the presence of the symptom, such as via a button press, can confound the observed activation.

A corollary to symptoms within a particular psychiatric disorder is to examine the same symptom in different disorders. This is particularly applicable in psychiatry as many symptoms, such as delusions, depression and hallucinations, occur in several distinct conditions. A series of functional neuroimaging studies examined the neural correlates of depression secondary to Huntington's disease and Parkinson's disease. Using ${ }^{18}$ FDG PET, Mayberg et al. $(1990,1992)$ found that bilateral hypometabolism of the orbital and inferior prefrontal and anterior temporal cortices was common to depressed patients with Huntington's and Parkinson's diseases, while Ring et al. (1994) reported bilateral decreased cerebral blood flow in the medial frontal and anterior cingulate cortices in depressed patients with Parkinson's disease. These correlates of depression may thus be independent of its aetiology and Mayberg (1994) suggested that disruption of pathways linking the frontal and temporal cortices and striatum may contribute to both primary depression and that associated with basal ganglia disease.

Dolan et al. (1993) examined the relationship between the neural correlates of psychomotor poverty in schizophrenia and psychomotor retardation in depression. Pooling $\mathrm{C}^{15} \mathrm{O}_{2}$ PET data from 40 patients in the resting state, they found that reduced regional cerebral blood flow in the left dorsolateral prefrontal cortex (DLPFG) was associated with psychomotor impairment, independent of diagnosis. Thus, there is some evidence that there may be common neural correlates for psychiatric symptoms irrespective of the disorder in which they occur.

\section{SYMPTOM PROVOCATION}

The pathophysiology of psychiatric symptoms can also be examined by provoking them experimentally and this method has been particularly employed in studies of anxiety disorders. Initial PET studies of acute anxiety, provoked by lactate in patients with panic disorder and by anticipation of an unpleasant stimulus in healthy controls, found an association with increased blood flow in the temporal poles bilaterally, which was common to both groups (Reiman et al. 1989a,b). However, a re-evaluation using co-registered structural magnetic resonance images showed that the changes in the temporal regions were localized to extracranial muscle and reflected subjects clenching their teeth in response to anxiety (Drevets et al. 1992b). Subsequent studies have incorporated a teethclenching control task to account for this possible confound and suggest that there is indeed a temporal polar response independent of extracranial muscle activity (Rauch et al. 1995, 1996).

Symptom provocation has also been used to study neural activity in OCD. Using $\mathrm{H}_{2}{ }^{15} \mathrm{O}$ PET, McGuire et al. (1994) exposed patients to a hierarchy of contaminants that elicited the urge to ritualize to varying degrees, then examined the relationship between symptom severity and cerebral blood flow. Positive correlations were evident in the inferior frontal gyrus, basal ganglia, thalamus, hippocampus and posterior cingulate cortex. Other studies have involved a categorical comparison of symptomprovoked and baseline states producing broadly similar results, using $\mathrm{C}^{15} \mathrm{O}_{2}$ PET (Rauch et al. 1994) and, more recently, functional magnetic resonance imaging (fMRI) (Breiter et al. 1996). These studies have thus indicated the brain areas that may mediate obsessional symptoms, although it is difficult to assess whether the regional changes are specific to obsessional phenomena or to other responses to provocation, particularly anxiety. Patients can rate obsessions and anxiety separately, but McGuire et al. (1994) found that the subjective ratings for anxiety and the urge to ritualize during scanning were almost identical. Another strategy would be to evoke potentially confounding components of the response separately, for example using a paradigm specific to anxiety as a reference condition. Alternatively, one can study patients with atypically 'pure' responses, such as patients with comorbid Tourette's disorder and OCD who often experience compulsive urges with less associated anxiety than patients with OCD alone (Miguel et al. 1997).

The neural correlates of specific phobia have been examined by the induction of anxiety with the feared object, for example a spider or a snake. Exposure to phobic stimuli has been associated with elevated blood flow in the visual association cortex and reduced cerebral blood flow in the hippocampus, prefrontal, orbitofrontal, temporopolar and posterior cingulate cortices (Wik et al. 1993; Fredrikson et al. 1995). O'Carroll et al. (1993) found a specific reduction of activity in the right temporaloccipital region, while Rauch et al. (1995) reported increased cerebral blood flow in the thalamus and posterior medial orbitofrontal, insular, anterior temporal, anterior cingulate and somatosensory cortices. Again, these disparate results may reflect methodological differences between groups as well as the variety of cognitive and emotional responses that can be associated with the provocation of anxiety, such as vocalization, increased vigilance and a desire to flee from the feared object. Using a similar paradigm in anorexia nervosa with exposure of patients to high calorie drinks in conjunction with fMRI, Ellison et al. (1998) found that patients experienced anxiety with the exposure and showed activation in the left insula, anterior cingulate and left amygdala-hippocampal regions, relative to healthy controls. In this case, interpretation of these results is complicated by the entwined symptoms of anxiety, disgust and a desire to avoid the source of the anxiety. The interpretation of these studies of exposure to feared objects, whether in specific phobia or anorexia nervosa, is complicated by their heterogeneous responses.

In an attempt to identify common regional correlates of anxiety across different disorders, Rauch et al. (1997) combined the data from 23 patients in provocation studies of OCD, specific phobia and post-traumatic stress disorder. They found that anxiety correlated with activation in the right inferior frontal and orbitofrontal cortices, insula, basal ganglia and brainstem bilaterally.

Symptom provocation has been less frequently employed in patients with psychotic disorders. Yet, in 
schizophrenia formal thought disorder can be provoked by asking patients to describe pictures the interpretation of which is ambiguous. This paradigm has been combined with functional imaging, permitting examination of neural activity while patients were articulating thoughtdisordered speech (McGuire et al. 1998) (figure 4). Symptom provocation can also be used to induce the analogues of psychiatric phenomena in healthy volunteers. Using $\mathrm{H}_{2}^{15} \mathrm{O}$ PET, Pardo et al. (1993) found that transient self-induced sadness was associated with activation of the inferior frontal and orbitofrontal cortices, while George et al. (1995) found that self-induced and face-simulated sadness was associated with activation in the cingulate, medial prefrontal and medial temporal cortices, as well as in the brainstem, thalamus and caudate. One limitation of this approach is that the measurement of mood changes depends on subjective ratings. In addition, in some studies the activation is potentially confounded by the memory recall required to induce the mood state (Squire \& Zola-Morgan 1991; Paradiso et al. 1997; Fletcher et al. 1998; Wagner et al. 1998). Nevertheless, these studies have helped to clarify the relationship between the brain areas involved in normal changes in mood and those implicated in the severe changes of depression and mania (George et al. 1995).

\section{SYMPTOM TRAITS}

An approach complementary to studying the correlates of active symptoms is to focus on patients with the trait for a given symptom, examining cognitive processes that are putatively defective in those with that predisposition. In these studies, the patient is typically in remission and comparisons are made with other patients who lack the trait in question. For example, McGuire et al. (1996b) compared the neural correlates of auditory verbal imagery in schizophrenic patients with a strong predisposition to auditory hallucinations (hallucinators) and those with no such history (non-hallucinators) as well as healthy controls. The hallucinators showed an abnormal pattern of activation in the lateral temporal cortex and supplementary motor area, consistent with the notion that auditory hallucinations are related to deficits in the processing of inner speech (figure 5). Woodruff et al. (1997) used a similar approach to compare temporal cortical responses to external speech in patients who were and were not prone to auditory hallucinations.

\section{PHARMACOLOGICAL CHALLENGES}

Psychiatric symptoms can also be provoked using pharmacological challenges. The illicit drug phencyclidine (PCP) produces behavioural and cognitive disturbances, including psychotic symptoms, in healthy persons. It is an antagonist at the $\mathcal{N}$-methyl-D-aspartic acid (NMDA) glutamate receptor. Ketamine is also an NMDA antagonist, but with lower potency, a shorter half-life and clinical use as an anaesthetic. Using $\mathrm{H}_{2}{ }^{15} \mathrm{O}$ PET, Lahti et al. (1995) examined the psychosis-inducing effects of a subanaesthetic dose of ketamine on schizophrenic patients, finding increased blood flow in the anterior cingulate cortex in association with a temporary exacerbation of their psychotic symptoms. However, a placebo-control infusion was not performed. Using ${ }^{18}$ FDG PET, Vollenweider et al. (1997) also found that ketamine led to increased glucose metabolism in the frontomedial and anterior cingulate cortices in association with induced psychotic symptoms in healthy volunteers, while Breier et al. (1997) reported a specific association of increased metabolism in the prefrontal cortex with the ketamine-induced thought disorder. These studies thus suggest that the medial prefrontal and anterior cingulate cortices may mediate psychotic symptoms and are consistent with the belief that abnormal glutamatergic neurotransmission is involved in the pathophysiology of psychosis.

Other groups have used the serotonergic agonist fenfluramine to probe the serotonergic system, which is believed to be dysregulated in depression (Mann et al. 1996; Meyer et al. 1998), partly because of the clinical efficacy of serotonin reuptake inhibitor medications. Mann et al. (1996) reported changes in activity in healthy subjects in the prefrontal and temporoparietal cortices, neither of which was evident in depressed patients. In contrast, Meyer et al. (1998) found no significant differences between depressed patients and healthy volunteers. Although these preliminary results are inconsistent, in part reflecting methodological differences, the approach remains heuristic.

Neuroimaging studies of pharmacological challenges have also been combined with cognitive tasks. Such paradigms may increase the likelihood of detecting drug effects by ensuring a greater uniformity in cognitive activity among different subjects during scanning as compared to the resting state. Fletcher et al. (1996) examined the effects of an apomorphine pharmacological challenge on activation during verbal fluency using $\mathrm{H}_{2}{ }^{15} \mathrm{O}$ PET. Apomorphine is a non-selective dopamine agonist which has a predominantly presynaptic effect at low dose, resulting in a net reduction of dopamine transmission, akin to the putative effects of anti-psychotic medications as dopamine receptor antagonists. During verbal fluency the schizophrenic patients failed to activate the anterior cingulate as compared to healthy controls; however, this was reversed following administration of apomorphine. This finding suggests that some functional abnormalities in schizophrenia may reflect abnormal dopamine transmission, consistent with the therapeutic effects of dopamine antagonists.

\section{TREATMENT STUDIES}

The pathophysiology of psychiatric disorders can also be investigated by examining the effects of treatment on brain activity which may reveal biological predictors of the therapeutic response. Successful antidepressant treatment in depression has been associated with the resolution of abnormally decreased resting activity in the left DLPFG (Martinot et al. 1990), anterior cingulate cortex and basal ganglia (Goodwin et al. 1993), left DLPFG, medial prefrontal and cingulate cortices (Bench et al. 1995) and left superior frontal, right temporal and bilateral parietal cortices (Ogura et al. 1998). Other groups have found that elevated anterior cingulate activity pre-treatment in depressed patients predicted a successful response to treatment with medication 
(a)
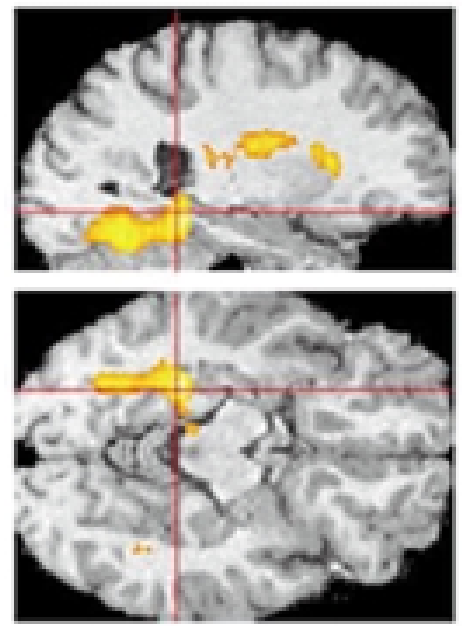

(b)
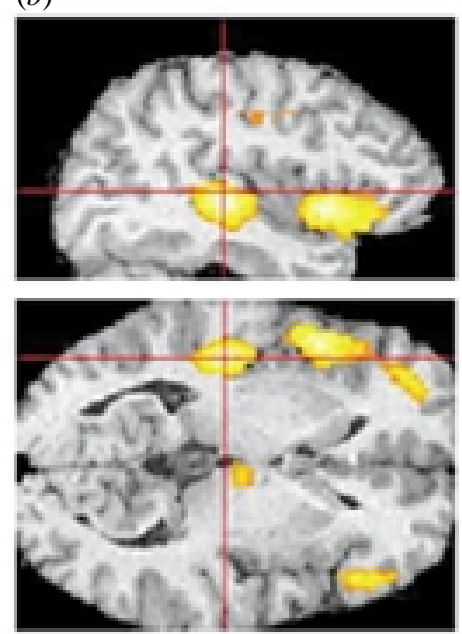
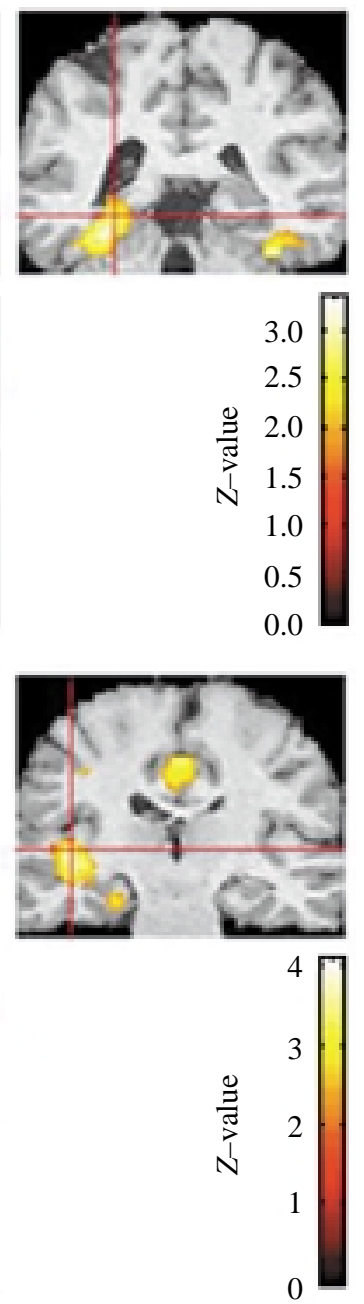

Figure 4. Brain areas where activity was correlated with 'positive' thought disorder in schizophrenia. $\mathrm{H}_{2}{ }^{15} \mathrm{O}$ PET data have been mapped onto a normal magnetic resonance image, sectioned to provide transverse, coronal and sagittal views. The left side of the brain is shown on the left side of the image. (a) The severity of thought disorder was positively correlated with activity around the junction of the left parahippocampal and fusiform gyri (marked by cross hairs) and in the anterior part of the right fusiform gyrus. (b) Thought disorder was negatively correlated with activity in the inferior frontal and cingulate cortices and in the left superior temporal gyrus (cross hairs). From McGuire et al. (1998).

(Mayberg et al. 1997) or sleep deprivation, with activity normalizing after sleep deprivation (Wu et al. 1992; Volk et al. 1997). Overall, treatment studies of depression have consistently implicated the anterior cingulate and prefrontal cortices, in particular the left DLPFC; however, the polarity of the abnormalities and changes has been inconsistent, perhaps reflecting paradigmatic differences, the contribution of both state and trait abnormalities and the aetiological heterogeneity of depression.

In OCD, Baxter et al. (1992) reported that treatment with either behaviour therapy or medication resulted in decreased caudate metabolism. They have since extended the sample, describing pre-treatment correlations in prefrontal cortico-striato-thalamic regions which were diminished following effective behavioural treatment (Schwartz 1998). Parallels are evident in the cingulatestriatal-pallidum-thalamic changes observed by Perani et al. (1995) in OCD patients pre- and post-treatment. These studies and those examining the effects of drug treatment and sleep deprivation in depression suggest that both pharmacological and psychological treatments can be clinically effective in specific psychiatric disorders and may produce similar effects on brain function. This raises the possibility that these fundamentally different forms of treatment may ultimately act on a common neural substrate.

\section{EVENT-RELATED DESIGNS}

Functional neuroimaging studies of cognitive tasks have classically involved blocked designs in which two or more conditions comprising several trials are compared. However, the correlates of a task can change with successive trials, for example as a result of the effects of practice or habituation (Jenkins et al. 1994). These time-related changes may not be evident in a blocked design, as the activation represents an average over several trials. fMRI permits scanning of multiple and repeated experimental trials of a task as it is not constrained by the risk of radiation exposure. Moreover, its temporal resolution allows the response to each trial to be examined separately. This should be particularly useful in the examination of transient phenomena, such as hallucinations, and of cognitive processes in disorders which can alter the patient's task response over time, for example through impaired learning or a failure to adopt a cognitive strategy.

\section{PRACTICAL ISSUES}

The behaviour of the subject is critical during neuroimaging studies and the disturbed behaviour that can be a feature of psychiatric disorders can occasionally result in surprising and undesirable effects. For example, MRI requires that no metallic objects are present on or in the subject; however, a paranoid patient may be reluctant to inform an investigator about a hidden knife, while a patient with dementia may have forgotten about a previous operation in which a synthetic cardiac valve was inserted. The development of claustrophobia during a scan may abruptly terminate a study and, although this can occur in healthy volunteers, it is a particular risk in patients with anxiety disorders. Similarly, while excessive head movement can result in artefacts in any subject, it can be especially problematic in patients who are agitated, disinhibited or have specific movement abnormalities, such as tardive dyskinesia or tics. Movement artefacts can also arise when subjects move while responding to a task, for example by pressing a button or speaking. This stimulus-correlated head motion may be simultaneous with the task-related neural response, thus confounding the observed activation and can be a particular problem in patients with schizophrenia (Bullmore $e t$ al. 1999) (figure 6).

Methods for minimizing head movement in the scanner have included moulded plastic masks to scalp braces and mouth bites, but it is often sufficient to ensure the comfort of the subject, with the head resting on a soft cushion and keeping the scan paradigms as short as possible (Williams et al. 1997). Ultimately, there is a tradeoff between the reduced movement resulting from 

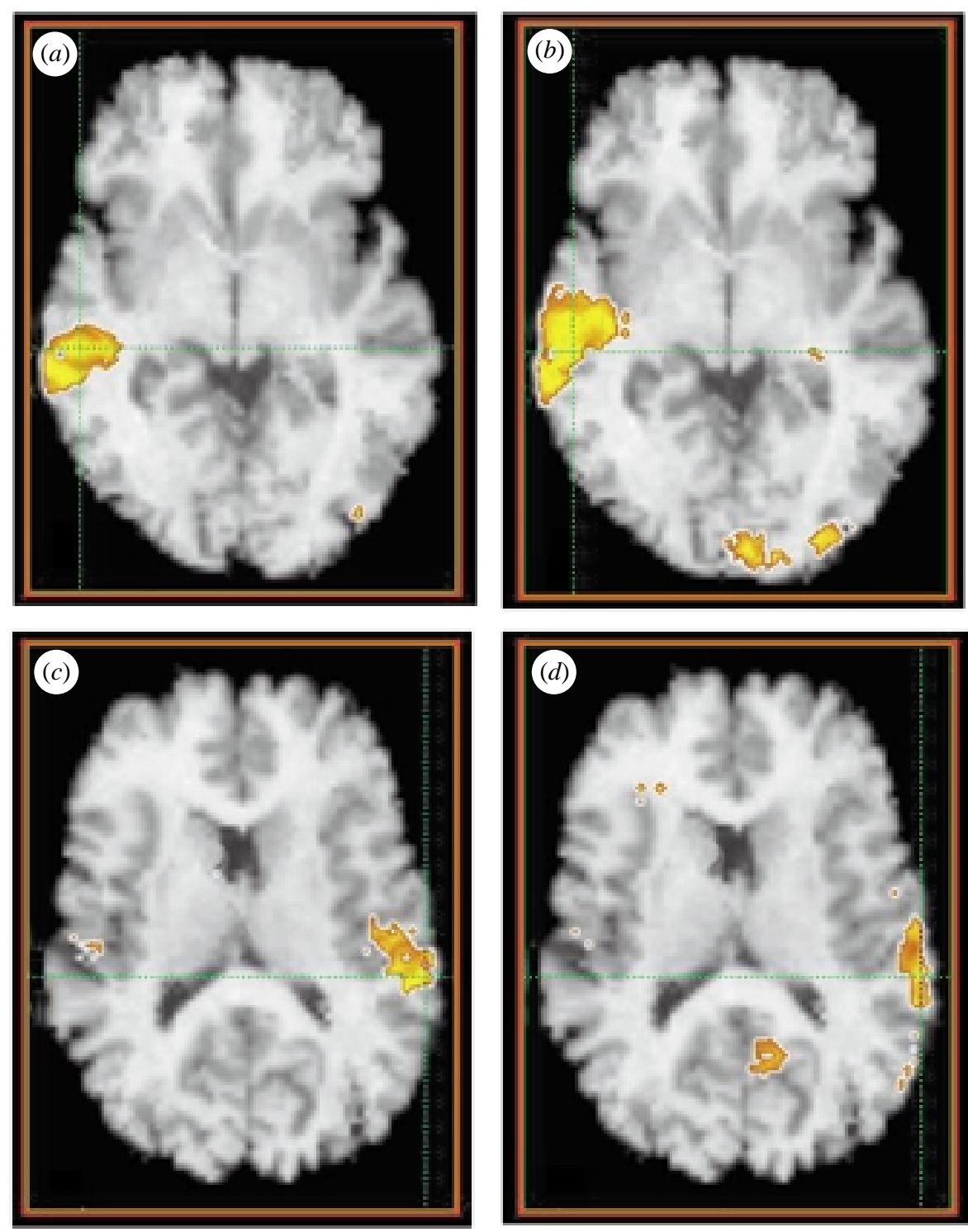

Figure 5. Differences in activation of the temporal cortex during auditory verbal imagery, as measured with ${ }^{15} \mathrm{O}_{2}$ PET. The data have been mapped onto a normal magnetic resonance image, with the left side of the brain shown on the left side of the image. When imagining another person speaking to them, patients with schizophrenia who were prone to auditory hallucinations differed from both controls and from patients who did not suffer from hallucinations, in showing $(a, b)$ significantly less activation in the left middle temporal gyrus, but $(c, d)$ greater activation in the right superior temporal gyrus. From McGuire et al. (1996b).

extreme restraint and the extent to which the restraint makes participation less attractive and comfortable. The minimization of scanning time has been greatly facilitated by the development of fMRI, which permits the completion of studies in a few minutes, as opposed to hours with SPET and PET.

Another important consideration in neuroimaging studies of psychiatric disorders is the ability of patients to provide informed consent. Psychiatric disorders can profoundly affect cognitive function and patients may be too psychotic, agitated or disorganized to cooperate with a neuroimaging paradigm. Consequently, the most severely ill patients may not be able to participate in imaging studies. As psychiatric disorders may also impair insight, the ability of patients to understand and appreciate the nature of the proposed investigation must be carefully assessed and their consent obtained without coercion.

Given these theoretical and practical difficulties, the study of psychiatric disorders with neuroimaging may appear daunting. However, although neuroimaging in some patients with psychiatric disorders is simply impracticable, in many patients it is eminently feasible, even in those with profound disturbances in mood or cognition (Bench et al. 1993; McGuire et al. 1993, 1998; Andreasen et al. 1997).

\section{SUMMARY AND FUTURE DIRECTIONS}

Investigations of the pathophysiology of psychiatric disorders have involved diverse and sometimes disparate techniques, including neuropathology, neuroendocrinology, neuropsychology, psychopharmacology and phenomenology. Functional neuroimaging offers the most direct means of investigating the neurobiology of psychiatric disorders in vivo, with the additional potential of integrating findings from these diverse disciplines. Neuroimaging is transforming our understanding and expanding public awareness of how the mind works in health and in illness.

The difficulties of studying psychiatric illnesses with neuroimaging range from the logistical implementation to designing paradigms which are sensitive and specific to a particular clinical sign or symptom. In fact, initial forays were met with scepticism as psychiatric illnesses were often viewed as disorders of the mind without 

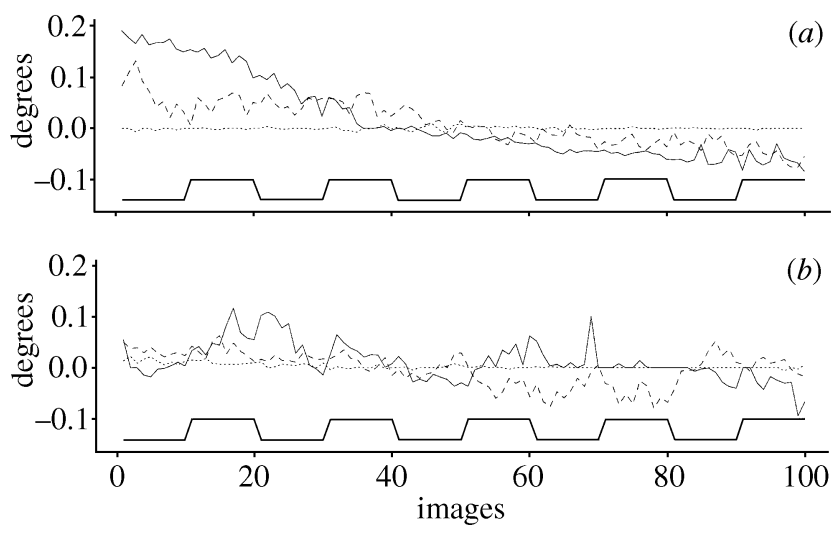

Figure 6. Rotational displacements of the head in groups of (a) healthy subjects and $(b)$ schizophrenic patients during an fMRI study of verbal fluency. Solid line, $x$-rotation; dashed line, $y$-rotation; dotted line, $z$-rotation. The square wave represents the two alternating task conditions. The pattern of head displacement over the $5 \mathrm{~min}$ of the study is different in patients and volunteers. In particular, the schizophrenic group show evidence of periodic $x$ - and $y$-rotation at the frequency of the input function. From Bullmore et al. (1999).

neurobiological correlates. Perhaps the main impact of functional imaging in psychiatric disorders to date has been to demonstrate that psychiatric disorders do indeed involve specific disturbances of brain function, to the extent that this is no longer an issue. However, to simply view psychiatric disorders in terms of brain pathophysiology would be excessively reductionistic and it is important to stress that the roles of cerebral dysfunction and biopsychosocial factors are not mutually exclusive. Rather, it is their complex interaction which ultimately results in the abnormalities of behaviour, cognition and mood that characterize psychiatric illnesses. The corollary is that treatment of psychiatric illnesses may be biological, psychological, or both, yet ultimately have a similar neurobiological effect.

A major difficulty in researching the basis of psychiatric illnesses is the likely aetiological heterogeneity of the disorders, which are still defined on purely clinical grounds, in contrast to many medical conditions. Furthermore, the symptomatology of a given psychiatric illness can change over time, as may any associated pathophysiology. For example, in manic depression, the overall course of illness is unpredictable, with a waxing and waning of symptoms. Investigation of these disorders can thus be complicated as their neural correlates may reflect a mixture of state and trait effects. However, the variability of symptoms over time and between patients also provides the opportunity to study the neural correlates of specific symptoms within a disorder. A future goal for psychiatry is to replace a diagnostic system based on phenomenology with one based on aetiology and pathophysiology, and neuroimaging offers a means of providing a basis for such reclassification. For example, the difficulty in clinically distinguishing between schizophrenia and an affective psychosis on the basis of symptomatology alone might be resolved if signs of fundamentally distinct pathophysiologies were discernible using neuroimaging.

The significance of the findings of functional imaging studies in psychiatry will also become clearer when their relationship to neuroanatomical changes is established.
For example, the relatively consistent finding of abnormal prefrontal activation in schizophrenia may reflect a localized pathology or a disturbance in its connections with other cortical or subcortical areas. The advent of fMRI means that structural and functional data can now be acquired with the same scanner, facilitating the integration of information on regional anatomy of activity. Studies of verbal fluency in schizophrenia have reported abnormal correlations between prefrontal activation and that in the temporal (Frith et al. 1995; Fletcher et al. 1996; Yurglen-Todd et al. 1996) and medial parietal cortices (Curtis et al. 1998; Spence et al. 1998), but, even with sophisticated path analyses, it is difficult to determine whether such correlations actually reflect interactions between the areas concerned (Bullmore et al. 1997). This issue might be addressed through examination of the anatomy of the connections themselves and this is now feasible using diffusion tensor imaging, which can measure the microscopic displacement of water molecules in neural tissues, revealing the orientation of axons within a given tract (Basser \& Pierpaoli 1996; Pierpaoli \& Basser 1996).

The potential for functional neuroimaging to have clinical applications is intriguing. In depression, schizophrenia and OCD, specific regional cerebral abnormalities have been associated with an effective response to treatment (Drevets et al. 1992a; Wu et al. 1992; Mayberg et al. 1997; Volk et al. 1997; Bartlett et al. 1998; Schwartz 1998). This kind of information may be used in the future to plan clinical management as well as the development and measurement of effective pharmacological and psychological treatments. Functional neuroimaging also has the potential to identify correlates of illness which are subclinical, perhaps preceding the onset of clinical symptoms or persisting after an apparent remission. The ability to detect brain changes in the absence of overt symptoms would be particularly useful in predicting which of the high-risk individuals are most likely to develop a psychiatric illness.

A broad overview of the current findings reveals some consistent findings, but much heterogeneity. This partly reflects the diversity of study paradigms and methods of analysis. Greater international collaboration could help to create a large database of normal and abnormal neuroimaging information, acquired and processed in a standardized manner. Further work might also be more closely integrated with research in other disciplines, such as genetics. For example, a deletion at q11 on chromosome 22 is associated with a $30 \%$ risk of developing psychosis, providing a unique opportunity of examining how a circumscribed genetic abnormality might affect the structure and function of the brain in subjects with and without psychosis (Chow et al. 1994; Van Amelsvoort et al. 1999).

Functional neuroimaging thus offers the most direct means of investigating psychiatric disorders in vivo and is transforming our understanding of the neurobiological underpinnings of the mind in health and in illness. Although much has been learned, the field is still in its infancy: study paradigms and imaging technology are becoming progressively sophisticated, larger groups of subjects are being investigated and the integration of functional and structural data is increasingly feasible. 
Future work is likely to clarify the pathophysiology of the major psychiatric disorders and lead to the first clinical applications of functional imaging in psychiatry.

\section{REFERENCES}

Andreasen, N. G., Rezai, K., Alliger, R., Swayze, V. W., Flaum, M., Kirchner, P., Cohen, G. \& O’Leary, D. S. 1992 Hypofrontality in neuroleptic-naive patients and in patients with chronic schizophrenia. Assessment with xenon 133 single-photon emission computed tomography and the Tower of London. Arch. Gen. Psychiatr. 49, 943-958.

Andreasen, N. G., O'Leary, D. S., Gizadlo, T., Arndt, S., Rezai, K., Watkins, G. L., Ponto, L. L. \& Hichwa, R. D. 1995 Remembering the past: two facets of episodic memory explored with positron emission tomography. Am. F. Psychiatr. 152, 1576-1585.

Andreasen, N. C., O'Leary, D. S., Flaum, M., Nopoulos, P., Watkins, G. L., Boles Ponto, L. L. \& Hichwa, R. D. 1997 Hypofrontality in schizophrenia: distributed dysfunctional circuits in neuroleptic-naive patients. Lancet 349, 1730-1734.

Austin, M. P., Dougall, N., Ross, M., Murray, C., O'Carroll, R. E., Moffoot, A., Ebmeier, K. P. \& Goodwin, G. M. 1992 Single photon emission tomography with 99 mTc-exametazime in major depression and the pattern of brain activity underlying the psychotic/neurotic continuum. F. Affect. Disord. 26, 31-43.

Bartlett, E. J., Brodie, J. D., Simkowitz, P., Schlosser, R., Dewey, S. L., Lindenmayer, J. P., Rusinek, H., Wolkin, A., Cancro, R. \& Schiffer, W. 1998 Effect of a haloperidol challenge on regional brain metabolism in neuroleptic-responsive and nonresponsive schizophrenic patients. Am. F. Psychiatr. 155, 337-343.

Basser, P. J. \& Pierpaoli, C. 1996 Microstructural and physiological features of tissues elucidated by quantitative-diffusiontensor MRI. 7. Magn. Reson. 111, 209-219.

Baxter Jr, L. R., Phelps, M. E., Mazziotta, J. C., Schwartz, J. M., Gerner, R. H., Selin, C. E. \& Sumida, R. M. 1985 Cerebral metabolic rates for glucose in mood disorders. Studies with positron emission tomography and fluorodeoxyglucose F 18. Arch. Gen. Psychiatr. 42, 441-447.

Baxter Jr, L. R., Phelps, M. E., Mazziotta, J. C., Guze, B. H., Schwartz, J. M. \& Selin, C. E. 1987 Local cerebral glucose metabolic rates in obsessive-compulsive disorder. A comparison with rates in unipolar depression and in normal controls. Arch. Gen. Psychiatr. 44, 211-218.

Baxter Jr, L. R., Schwartz, J. M., Mazziotta, J. C., Phelps, M. E., Pahl, J. J., Guze, B. H. \& Fairbanks, L. 1988 Cerebral glucose metabolic rates in nondepressed patients with obsessivecompulsive disorder. Am. 7. Psychiatr. 145, 1560-1563.

Baxter Jr, L. R., Schwartz, J. M., Phelps, M. E., Mazziotta, J. C., Guze, B. H., Selin, C. E., Gerner, R. H. \& Sumida, R. M. 1989 Reduction of prefrontal cortex glucose metabolism common to three types of depression. Arch. Gen. Psychiatr. 46, 243-250.

Baxter Jr, L. R. (and 10 others) 1992 Caudate glucose metabolic rate changes with both drug and behavior therapy for obsessive-compulsive disorder. Arch. Gen. Psychiatr. 49, 681-689.

Bench, G. J., Friston, K. J., Brown, R. G., Scott, L. C., Frackowiak, R. S. \& Dolan, R. J. 1992 The anatomy of melancholia: focal abnormalities of cerebral blood flow in major depression. Psychol. Med. 22, 607-615.

Bench, G. J., Friston, K. J., Brown, R. G., Frackowiak, R. S. \& Dolan, R. 1993 Regional cerebral blood flow in depression measured by positron emission tomography: the relationship with clinical dimensions. Psychol. Med. 23, 579-590.
Bench, C. J., Frackowiak, R. S. \& Dolan, R. J. 1995 Changes in regional cerebral blood flow on recovery from depression. Psychol. Med. 25, 247-261.

Berman, K. F., Zec, R. F. \& Weinberger, D. R. 1986 Physiologic dysfunction of dorsolateral prefrontal cortex in schizophrenia. II. Role of neuroleptic treatment, attention, and mental effort. Arch. Gen. Psychiatr. 43, 126-135.

Berman, K. F., Doran, A. R., Pickar, D. \& Weinberger, D. R. 1993 Is the mechanism of prefrontal hypofunction in depression the same as in schizophrenia? Br. F. Psychiatr. 162, 183-192.

Biver, F., Goldman, S., Delvenne, V., Luxen, A., De Maertelaer, V., Hubain, P., Mendlewicz, J. \& Lotstra, F. 1994 Frontal and parietal metabolic disturbances in unipolar depression. Biol. Psychiatr. 36, 381-388.

Breier, A., Malhotra, A. K., Pinals, D. A., Weisenfeld, N. I. \& Pickar, D. 1997 Association of ketamine-induced psychosis with focal activation of the prefrontal cortex in healthy volunteers. Am. F. Psychiatr. 154, 805-811.

Breiter, H. C. (and 16 others) 1996 Functional magnetic resonance imaging of symptom provocation in obsessivecompulsive disorder. Arch. Gen. Psychiatr. 53, 595-606.

Brodie, J. D. (and 12 others) 1984 Patterns of metabolic activity in the treatment of schizophrenia. Ann. Neurol. 15 (Suppl.), S166-S169.

Buchsbaum, M. S. (and 12 others) 1982 Cerebral glucography with positron tomography. Use in normal subjects and in patients with schizophrenia. Arch. Gen. Psychiatr. 39, 251-259.

Buchsbaum, M. S., Wu, J., DeLisi, L. E., Holcomb, H., Kessler, R., Johnson, J., King, A. C., Hazlett, E., Langston, K. \& Post, R. M. 1986 Frontal cortex and basal ganglia metabolic rates assessed by positron emission tomography with $[18 \mathrm{~F}] 2-$ deoxyglucose in affective illness. F. Affect. Disord. 10, 137-152.

Buchsbaum, M. S., Wu, J. C., DeLisi, L. E., Holcomb, H. H., Hazlett, E., Cooper-Langston, K. \& Kessler, R. 1987 Positron emission tomography studies of basal ganglia and somatosensory cortex neuroleptic drug effects: differences between normal controls and schizophrenic patients. Biol. Psychiatr. 22, 479-494.

Buchsbaum, M. S. (and 12 others) 1992 Striatal metabolic rate and clinical response to neuroleptics in schizophrenia. Arch. Gen. Psychiatr. 49, 966-974.

Bullmore, E. T., Frangou, S. \& Murray, R. M. 1997 The dysplastic net hypothesis: an integration of developmental and dysconnectivity theories of schizophrenia. Schizophr. Res. 28, 143-156.

Bullmore, E. T., Brammer, M. J., Rabe-Hesketh, S., Curtis, V. A., Morris, R. G., Williams, S. C. R., Sharma, T. \& McGuire, P. K. 1999 Methods for diagnosis and treatment of stimulus correlated motion in generic brain activation studies using fMRI. Hum. Brain Mapp. 7, 38-48.

Chabrol, H., Guell, A., Bes, A. \& Moron, P. 1986 Cerebral blood flow in schizophrenic adolescents. Am. F. Psychiatr. 143, 130.

Chow, E. W., Bassett, A. S. \& Weksberg, R. 1994 Velocardio-facial syndrome and psychotic disorders: implications for psychiatric genetics. Am. F. Med. Genet. 54, 107-112.

Cleghorn, J. M., Garnett, E. S., Nahmias, C., Firnau, G., Brown, G. M., Kaplan, R., Szechtman, H. \& Szechtman, B. 1989 Increased frontal and reduced parietal glucose metabolism in acute untreated schizophrenia. Psychiatr. Res. 28, 119-133.

Gleghorn, J. M., Franco, S., Szechtman, B., Kaplan, R. D., Szechtman, H., Brown, G. M., Nahmias, C. \& Garnett, E. S. 1992 Toward a brain map of auditory hallucinations. Am. F. Psychiatr. 149, 1062-1069.

Cohen, R. M., Nordahl, T. E., Semple, W. E., Andreason, P., Litman, R. E. \& Pickar, D. 1997 The brain metabolic patterns 
of clozapine- and fluphenazine-treated patients with schizophrenia during a continuous performance task. Arch. Gen. Psychiatr. 54, 481-486.

Curtis, V. A., Bullmore, E. T., Brammer, M. J., Wright, I. C., Williams, S. G. R., Morris, R. G., Sharma, T. S., Murray, R. M. \& McGuire, P. K. 1998 Attenuated frontal activation during a verbal fluency task in patients with schizophrenia. Am. F. Psychiatr. 155, 1056-1063.

Curtis, V. A., Bullmore, E. T., Morris, R. G., Brammer, M. J., Williams, S. C. R., Simmons, A., Sharma, T., Murray, R. M. \& McGuire, P. K. 1999 Attenuated frontal activation in schizophrenia may be task dependent. Schizophr. Res. 37, 35-44.

Dolan, R. J., Bench, G. J., Liddle, P. F., Friston, K. J., Frith, C. D., Grasby, P. M. \& Frackowiak, R. S. 1993 Dorsolateral prefrontal cortex dysfunction in the major psychoses; symptom or disease specificity? 7. Neurol. Neurosurg. Psychiatr. 56, 1290-1294.

Drevets, W. C., Videen, T. O., Price, J. L., Preskorn, S. H., Carmichael, S. T. \& Raichle, M. E. 1992a A functional anatomical study of unipolar depression. F. Neurosci. 12, 3628-3641.

Drevets, W. G., Videen, T. O., MacLeod, A. K., Haller, J. W. \& Raichle, M. E. $1992 b$ PET images of blood flow changes during anxiety; correction. Science 256, 1696.

Drevets, W. C., Price, J. L., Simpson Jr, J. R., Todd, R. D., Reich, T., Vannier, M. \& Raichle, M. E. 1997 Subgenual prefrontal cortex abnormalities in mood disorders. Nature 386, 824-827.

Early, T. S., Reiman, E. M., Raichle, M. E. \& Spitznagel, E. L. 1987 Left globus pallidus abnormality in never-medicated patients with schizophrenia. Proc. Natl Acad. Sci. USA 84, 561-563.

Ebmeier, K. P., Blackwood, D. H., Murray, C., Souza, V., Walker, M., Dougall, N., Moffoot, A. P., O'Carroll, R. E. \& Goodwin, G. M. 1993 Single-photon emission computed tomography with 99mTc-exametazime in unmedicated schizophrenic patients. Biol. Psychiatr. 33, 487-495.

Ellison, Z., Foong, J., Howard, R., Bullmore, E., Williams, S. \& Treasure, J. 1998 Functional anatomy of calorie fear in anorexia nervosa. Lancet 352, 1192.

Farkas, T., Wolf, A. P., Jaeger, J., Brodie, J. D., Christman, D. R. \& Fowler, J. S. 1984 Regional brain glucose metabolism in chronic schizophrenia. A positron emission transaxial tomographic study. Arch. Gen. Psychiatr. 41, 293-300.

Fletcher, P. C., Frith, C. D., Grasby, P. M., Friston, K. J. \& Dolan, R. J. 1996 Local and distributed effects of apomorphine on fronto-temporal function in acute unmedicated schizophrenia. F. Neurosci. 16, 7055-7066.

Fletcher, P. C., McKenna, P. J., Frith, C. D., Grasby, P. M., Friston, K. J. \& Dolan, R. J. 1998 Brain activations in schizophrenia during a graded memory task studied with functional neuroimaging. Arch. Gen. Psychiatr. 55, 1001-1008.

Fredrikson, M., Wik, G., Annas, P., Ericson, K. \& StoneElander, S. 1995 Functional neuroanatomy of visually elicited simple phobic fear: additional data and theoretical analysis. Psychophysiology 32, 43-48.

Frith, C. D., Friston, K. J., Herold, S., Silbersweig, D., Fletcher, P., Cahill, C., Dolan, R. J., Frackowiak, R. S. J. \& Liddle, P. F. 1995 Regional brain activity in chronic schizophrenic patients during the performance of a verbal fluency task. Br. 7. Psychiatr. 167, 343-349.

Gelder, M. G. 1996 Biological psychiatry in perspective. $\mathrm{Br}$. Med. Bull. 52, 401-407.

George, M. S., Ketter, T. A., Parekh, P. I., Horwitz, B., Herscovitch, P. \& Post, R. M. 1995 Brain activity during transient sadness and happiness in healthy women. $A m . \mathcal{F}$. Psychiatr. 152, 341-351.
Geraud, G., Arne-Bes, M. C., Guell, A. \& Bess, A. 1987 Reversibility of hemodynamic hypofrontality in schizophrenia. 7. Cerebr. Blood-Flow Metab. 7, 9-12.

Goldberg, T. E., Berman, K. F., Mohr, E. \& Weinberger, D. R. 1990 Regional cerebral blood flow and cognitive function in Huntington's disease and schizophrenia. A comparison of patients matched for performance on a prefrontal-type task. Arch. Neurol. 47, 418-422.

Goodwin, G. M., Austin, M. P., Dougall, N., Ross, M., Murray, C., O'Carroll, R. E., Moffoot, A., Prentice, N. \& Ebmeier, K. P. 1993 State changes in brain activity shown by the uptake of $99 \mathrm{~m} T \mathrm{c}$-exametazime with single photon emission tomography in major depression before and after treatment. 7. Affect. Disord. 29, 243-253.

Gur, R. E., Skolnick, B. E., Gur, R. C., Caroff, S., Rieger, W., Obrist, W. D., Younkin, D. \& Reivich, M. 1983 Brain function in psychiatric disorders. I. Regional cerebral blood flow in medicated schizophrenics. Arch. Gen. Psychiatr. 43, $1250-1254$.

Gur, R. E., Skolnick, B. E., Gur, R. C., Caroff, S., Rieger, W., Obrist, W. D., Younkin, D. \& Reivich, M. 1984 Brain function in psychiatric disorders. II. Regional cerebral blood flow in medicated unipolar depressives. Arch. Gen. Psychiatr. 41, 695-699.

Gur, R. E., Gur, R. C., Skolnick, B. E., Caroff, S., Obrist, W. D., Resnick, S. \& Reivich, M. 1985 Brain function in psychiatric disorders. III. Regional cerebral blood flow in unmedicated schizophrenics. Arch. Gen. Psychiatr. 42, 329-334.

Gur, R. E. (and 10 others) 1987a Regional brain function in schizophrenia. I. A positron emission tomography study. Arch. Gen. Psychiatr. 44, 119-125.

Gur, R. E., Resnick, S. M., Gur, R. C., Alavi, A., Caroff, S., Kushner, M. \& Reivich, M. $1987 b$ Regional brain function in schizophrenia. II. Repeated evaluation with positron emission tomography. Arch. Gen. Psychiatr. 44, 126-129.

Holcomb, H. H., Cascella, N. G., Thaker, G. K., Medoff, D. R., Dannals, R. F. \& Tamminga, C. A. 1996 Functional sites of neuroleptic drug action in the human brain: PET/ FDG studies with and without haloperidol. Am. F. Psychiatr. 153, 41-49.

Hurwitz, T. A., Clark, C., Murphy, E., Klonoff, H., Martin, W. R. W. \& Pate, B. D. 1990 Regional cerebral glucose metabolism in major depressive disorder. Can. F. Psychiatr. 35, 684-688.

Ingvar, D. H. \& Franzen, G. 1974 Distribution of cerebral activity in chronic schizophrenia. Lancet 2, 1484-1486.

Jenkins, I., Brooks, D., Nixon, P., Frackowiak, R. \& Passingham, R. 1994 Motor sequence learning: a study with positron emission tormography. F. Neurosci. 14, 3775-3790.

Kishimoto, H. (and 12 others) 1987 Three subtypes of chronic schizophrenia identified using ${ }^{11} \mathrm{C}$-glucose positron emission tomography. Psychiatr. Res. 21, 285-292.

Kling, A. S., Metter, E. J., Riege, W. H. \& Kuhl, D. E. 1986 Comparison of PET measurement of local brain glucose metabolism and CAT measurement of brain atrophy in chronic schizophrenia and depression. Am. F. Psychiatr. 143, $175-180$.

Kurachi, M., Kobayashi, K., Matsubara, R., Hiramatsu, H., Yamaguchi, N., Matsuda, H., Maeda, T. \& Hisada, K. 1985 Regional cerebral blood flow in schizophrenic disorders. Eur. Neurol. 24, 176-181.

Lahti, A. C., Holcomb, H. H., Medoff, D. R. \& Tamminga, C. A. 1995 Ketamine activates psychosis and alters limbic blood flow in schizophrenia. NeuroReport 6, 869-872.

Liddle, P. F., Friston, K. J., Frith, C. D., Hirsch, S. R., Jones, T. \& Frackowiak, R. S. 1992 Patterns of cerebral blood flow in schizophrenia. Br. F. Psychiatr. 160, 179-186. 
McGuire, P. K., Shah, G. M. \& Murray, R. M. 1993 Increased blood flow in Broca's area during auditory hallucinations in schizophrenia. Lancet 342, 703-706.

McGuire, P. K., Bench, C. J., Frith, C. D., Marks, I. M., Frackowiak, R. S. \& Dolan, R. J. 1994 Functional anatomy of obsessive-compulsive phenomena. Br. F. Psychiatr. 164, 459-468.

McGuire, P. K., Paulesu, E., Frackowiak, R. S. \& Frith, C. D. $1996 a$ Brain activity during stimulus independent thought. NeuroReport 7, 2095-2099.

McGuire, P. K., Silbersweig, D. A., Wright, I. C. \& Murray, R. M. $1996 b$ The neural correlates of inner speech and auditory verbal imagery in schizophrenia: relationship to auditory verbal hallucinations. Br. F. Psychiatr. 169, 148-159.

McGuire, P. K., Quested, D. J., Spence, S. A., Murrary, R. M., Frith, G. D. \& Liddle, P. S. 1998 Pathophysiology of 'positive' thought disorder in schizophrenia. Br. F. Psychiatr. 173, 231-235

Mann, J. J., Malone, K. M., Diehl, D. J., Perel, J., Cooper, T. B. \& Mintun, M. A. 1996 Demonstration in vivo of reduced serotonin responsivity in the brain of untreated depressed patients. Am. F. Psychiatr. 153, 174-182.

Martinot, J. L., Hardy, P., Feline, A., Huret, J. D., Mazoyer, B., Attar-Levy, D., Pappata, S. \& Syrota, A. 1990 Left prefrontal glucose hypometabolism in the depressed state: a confirmation. Am. F. Psychiatr. 147, 1313-1317.

Mathew, R. J., Duncan, G. C., Weinman, M. L. \& Barr, D. L. 1982 Regional cerebral blood flow in schizophrenia. Arch. Gen. Psychiatr. 39, 1121-1124.

Mathew, R. J., Wilson, W. H., Tant, S. R., Robinson, L. \& Prakash, R. 1988 Abnormal resting regional cerebral blood flow patterns and their correlates in schizophrenia. Arch. Gen. Psychiatr. 45, 542-549.

Mayberg, H. S. 1994 Frontal lobe dysfunction in secondary depression. 7. Neuropsychiatr. Clin. Neurosci. 6, 428-442.

Mayberg, H. S., Starkstein, S. E., Sadzot, B., Preziosi, T., Andrezejewski, P. L., Dannals, R. F., Wagner Jr, H. N. \& Robinson, R. G. 1990 Selective hypometabolism in the inferior frontal lobe in depressed patients with Parkinson's disease. Ann. Neurol. 28, 57-64.

Mayberg, H. S., Starkstein, S. E., Peyser, C. E., Brandt, J., Dannals, R. F. \& Folstein, S. E. 1992 Paralimbic frontal lobe hypometabolism in depression associated with Huntington's disease. Neurology 42, 1791-1797.

Mayberg, H. S. (and 10 others) 1997 Cingulate function in depression: a potential predictor of treatment response. NeuroReport 8, 1057-1061.

Mazziotta, J. C., Phelps, M. E., Carson, R. E. \& Kuhl, D. E. 1992 Tomographic mapping of human cerebral metabolism: sensory deprivation. Ann. Neurol. 12, 435-444.

Meyer, J. H., Kennedy, S. \& Brown, G. M. 1998 No effect of depression on $\left[(15) \mathrm{O} \mathrm{H}_{2} \mathrm{O}\right.$ PET response to intravenous d-fenfluramine. Am. F. Psychiatr. 155, 1241-1246.

Miguel, E. C., Baer, L., Coffey, B. J., Rauch, S. L., Savage, G. R., O’Sullivan, R. L., Phillips, K., Moretti, C., Leckman, J. F. \& Jenike, M. A. 1997 Phenomenological differences appearing with repetitive behaviours in obsessive-compulsive disorder and Gilles de la Tourette's syndrome. Br. F. Psychiatr. 170, 140-145.

Miller, D. D., Andreasen, N. G., O'Leary, D. S., Rezai, K., Watkins, G. L., Ponto, L. L. \& Hichwa, R. D. 1997 Effect of antipsychotics on regional cerebral blood flow measured with positron emission tomography. Neuropsychopharmacology 17, 230-240.

Nordahl, T. E., Benkelfat, C., Semple, W. E., Gross, M., King, A. C. \& Cohen, R. M. 1989 Cerebral glucose metabolic rates in obsessive compulsive disorder. Neuropsychopharmacology 2, 23-28.
O'Carroll, R. E., Moffoot, A. P., Van Beck, M., Dougall, N., Murray, G., Ebmeier, K. P. \& Goodwin, G. M. 1993 The effect of anxiety induction on the regional uptake of 99mTc-exametazime in simple phobia as shown by single photon emission tomography (SPET). F. Affect. Disord. 28, 203-210.

Ogura, A., Morinobu, S., Kawakatsu, S., Totsuka, S. \& Komatani, A. 1998 Changes in regional brain activity in major depression after successful treatment with antidepressant drugs. Acta Psychiatr. Scand. 98, 54-59.

Paradiso, S., Crespo Facorro, B., Andreasen, N. C., O'Leary, D. S., Watkins, L. G., Boles Ponto, L. L. \& Hichwa, R. D. 1997 Brain activity assessed with PET during recall of word lists and narratives. NeuroReport 8, 3091-3096.

Pardo, J. V., Pardo, P. J. \& Raichle, M. E. 1993 Neural correlates of self-induced dysphoria. Am. F. Psychiatr. 150, 713-719.

Perani, D., Colombo, C., Bressi, S., Bonfanti, A., Grassi, F., Scarone, S., Bellodi, L., Smeraldi, E. \& Fazio, F. 1995 [18F]FDG PET study in obsessive-compulsive disorder: a clinical/metabolic correlation study after treatment. $B r . \mathcal{F}$. Psychiatr. 166, 244-250.

Pierpaoli, C. \& Basser, P. J. 1996 Toward a quantitative assessment of diffusion anisotropy. Magn. Reson. Med. 36, 893-906.

Rauch, S. L., Jenike, M. A., Alpert, N. M., Baer, L., Breiter, H. C., Savage, C. R. \& Fischman, A. J. 1994 Regional cerebral blood flow measured during symptom provocation in obsessive-compulsive disorder using oxygen 15-labeled carbon dioxide and positron emission tomography. Arch. Gen. Psychiatr. 51, 62-70.

Rauch, S. L., Savage, C. R., Alpert, N. M., Miguel, E. C., Baer, L., Breiter, H. C., Fischman, A. J., Manzo, P. A., Moretti, C. \& Jenike, M. A. 1995 A positron emission tomographic study of simple phobic symptom provocation. Arch. Gen. Psychiatr. 52, 20-28.

Rauch, S. L., Van der Kolk, B. A., Fisler, R. E., Alpert, N. M., Orr, S. P., Savage, C. R., Fischman, A. J., Jenike, M. A. \& Pitman, R. K. 1996 A symptom provocation study of posttraumatic stress disorder using positron emission tomography and script-driven imagery. Arch. Gen. Psychiatr. 53, 380-387.

Rauch, S. L., Savage, C. R., Alpert, N. M., Fischman, A. J. \& Jenike, M. A. 1997 The functional neuroanatomy of anxiety: a study of three disorders using positron emission tomography and symptom provocation. Biol. Psychiatr. 42, 446-452.

Reiman, E. M., Fusselman, M. J., Fox, P. T. \& Raichle, M. E. 1989 a Neuroanatomical correlates of anticipatory anxiety. Science 243, 1071-1074.

Reiman, E. M., Raichle, M. E., Robins, E., Mintun, M. A., Fusselman, M. J., Fox, P. T., Price, J. L. \& Hackman, K. A. $1989 b$ Neuroanatomical correlates of a lactate-induced anxiety attack. Arch. Gen. Psychiatr. 46, 493-500.

Ring, H. A., Bench, C. J., Trimble, M. R., Brooks, D. J., Frackowiak, R. S. \& Dolan, R. J. 1994 Depression in Parkinson's disease. A positron emission study. Br. F. Psychiatr. 165, 333-339.

Sackeim, H. A., Prohovnik, I., Moeller, J. R., Brown, R. P., Apter, S., Prudic, J., Devanand, D. P. \& Mukherjee, S. 1990 Regional cerebral blood flow in mood disorders. I. Comparison of major depressives and normal controls at rest. Arch. Gen. Psychiatr. 47, 60-70.

Saxena, S., Brody, A. L., Schwartz, J. M. \& Baxter, L. R. 1998 Neuroimaging and frontal-subcortical circuitry in obsessivecompulsive disorder. Br. F. Psychiatr. 35 (Suppl.), 26-37.

Schwartz, J. M. 1998 Neuroanatomical aspects of cognitivebehavioural therapy response in obsessive-compulsive disorder. An evolving perspective on brain and behaviour. Br. 7. Psychiatr. 35 (Suppl.), 38-44.

Scottish Schizophrenia Research Group 1998 Regional cerebral blood flow in first-episode schizophrenia patients before and 
after antipsychotic drug treatment. Acta Psychiatr. Scand. 97, 440-449.

Sheppard, G., Gruzelier, J., Manchanda, R., Hirsch, S. R., Wise, R., Frackowiak, R. \& Jones, T. $1983{ }^{15} \mathrm{O}$ positron emission tomographic scanning in predominantly nevertreated acute schizophrenic patients. Lancet 2, 1448-1452.

Silbersweig, D. A. (and 11 others) 1995 A functional neuroanatomy of hallucinations in schizophrenia. Nature 378, $176-179$.

Silfverskiold, P. \& Risberg, J. 1989 Regional cerebral blood flow in depression and mania. Arch. Gen. Psychiatr. 46, 253-259.

Spence, S. A., Hirsch, S. R., Brooks, D. J. \& Grasby, P. M. 1998 Prefrontal cortex activity in people with schizophrenia and control subjects: evidence from positron emission tomography for remission of 'hypofrontality' with recovery from acute schizophrenia. Br. F. Psychiatr. 172, 316-323.

Squire, L. R. \& Zola-Morgan, M. S. 1991 The medial temporal lobe memory system. Science 253, 1380-1386.

Swedo, S. E., Schapiro, M. B., Grady, C. L., Cheslow, D. L., Leonard, H. L., Kumar, A., Friedland, R., Rapoport, S. I. \& Rapoport, J. L. 1989 Cerebral glucose metabolism in childhood-onset obsessive-compulsive disorder. Arch. Gen. Psychiatr. 46, 518-523.

Szechtman, H., Nahmias, C., Garnett, E. S., Firnau, G., Brown, G. M., Kaplan, R. D. \& Cleghorn, J. M. 1988 Effect of neuroleptics on altered cerebral glucose metabolism in schizophrenia. Arch. Gen. Psychiatr. 45, 523-532.

Van Amelsvoort, T., Daly, E., Critchley, H. D., Robertson, D., Murphy, K., Simmons, A., Owen, M. \& Murphy, D. 1999 A human genetic model for schizophrenia: brain structure and function of people with velo-cardio-facial syndrome. Schizophr. Res. 36, 213.

Vita, A., Bressi, S., Perani, D., Invernizzi, G., Giobbio, G. M., Dieci, M., Garbarini, M., Del Sole, A. \& Fazio, F. 1995 High-resolution SPECT study of regional cerebral blood flow in drug-free and drug-naive schizophrenic patients. Am. $\mathcal{F}$. Psychiatr. 152, 876-882.

Volk, S. A., Kaendler, S. H., Hertel, A., Maul, F. D., Manoocheri, R., Weber, R., Georgi, K., Pflug, B. \& Hor, G. 1997 Can response to partial sleep deprivation in depressed patients be predicted by regional changes of cerebral blood flow? Psychiatr. Res. 75, 67-74.

Volkow, N. D., Wolf, A. P., Van Gelder, P., Brodie, J. D., Overall, J. E., Cancro, R. \& Gomez-Mont, F. 1987 Phenomenological correlates of metabolic activity in 18 patients with chronic schizophrenia. Am. F. Psychiatr. 144, 151-158.

Vollenweider, F. X., Leenders, K. L., Scharfetter, C., Antonini, A., Maguire, P., Missimer, J. \& Angst, J. 1997 Metabolic hyperfrontality and psychopathology in the ketamine model of psychosis using positron emission tomography (PET) and $\left[{ }^{18} \mathrm{~F}\right]$ fluorodeoxyglucose (FDG). Eur. Neuropsychopharmacol. 7, 9-24.

Wagner, A. D., Schacter, D. L., Rotte, M., Koutstaal, W., Maril, A., Dale, A. M., Rosen, B. R. \& Buckner, R. L. 1998
Building memories: remembering and forgetting of verbal experiences as predicted by brain activity. Science 281, 1188-1191.

Weinberger, D. R. \& Berman, K. F. 1996 Prefrontal function in schizophrenia: confounds and controversies. Phil. Trans. R. Soc. Lond. B 351, 1495-1503.

Weinberger, D. R., Berman, K. F. \& Zec, R. F. 1986 Physiologic dysfunction of dorsolateral prefrontal cortex in schizophrenia. I. Regional cerebral blood flow evidence. Arch. Gen. Psychiatr. 43, 114-124.

Weinberger, D. R., Berman, K. F., Iadarola, M., Driesen, N. \& Zec, R. F. 1988 Prefrontal cortical blood flow and cognitive function in Huntington's disease. F. Neurol. Neurosurg. Psychiatr. 51, 94-104.

Widen, L. (and 14 others) 1983 PET studies of glucose metabolism in patients with schizophrenia. Am. F. Neuroradiol. 4, $550-552$.

Wik, G., Wiesel, F. A., Sjogren, I., Blomqvist, G., Greitz, T. \& Stone-Elander, S. 1989 Effects of sulpiride and chlorpromazine on regional cerebral glucose metabolism in schizophrenic patients as determined by positron emission tomography. Psychopharmacology (Berl.) 97, 309-318.

Wik, G., Fredrikson, M., Ericson, K., Eriksson, L., StoneElander, S. \& Greitz, T. 1993 A functional cerebral response to frightening visual stimulation. Psychiatr. Res. 50, $15-24$.

Williams, S. C. R., Simmons, A., Andrew, C. M., Brammer, M. J., Bullmore, E. T. \& Rabe-Hesketh, S. 1997 Brain activation studies using magnetic resonance imaging. In Advances in neurochemistry (ed. H. S. Bachelard), pp. 241-265. New York: Plenum Press.

Wolkin, A., Jaeger, J., Brodie, J. D., Wolf, A. P., Fowler, J., Rotrosen, J., Gomez-Mount, F. \& Cancro, R. 1985 Persistence of cerebral metabolic abnormalities in chronic schizophrenia as determined by positron emission tomography. Am. F. Psychiatr. 142, 564-571.

Wolkin, A., Sanfilipo, M., Duncan, E., Angrist, B., Wolf, A. P., Cooper, T. B., Brodie, J. D., Laska, E. \& Rotrosen, J. P. 1996 Blunted change in cerebral glucose utilization after haloperidol treatment in schizophrenic patients with prominent negative symptoms. Am. F. Psychiatr. 153, 346-354.

Woodruff, P. W., Wright, I. C., Shuriquie, N., Russouw, H., Rushe, T., Howard, R. J., Graves, M., Bullmore, E. T. \& Murray, R. M. 1997 Structural brain abnormalities in male schizophrenics reflect fronto-temporal dissociation. Psychol. Med. 27, 1257-1266.

Wu, J. C., Gillin, J. C., Buchsbaum, M. S., Hershey, T., Johnson, J. C. \& Bunney Jr, W. E. 1992 Effect of sleep deprivation on brain metabolism of depressed patients. Am. $\mathcal{F}$. Psychiatr. 149, 538-543.

Yurglen-Todd, D., Waternaux, C., Cohen, B., Gruber, S., English, C. \& Renshaw, P. 1996 Functional magnetic resonance imaging of schizophrenic patients during word production. Am. F. Psychiatr. 153, 200-205. 